\title{
Professores de uma escola pública paulista analisam o Exame Nacional do Ensino Médio (ENEM)
}

\section{Teachers from São Paulo's public schoolss analyse the High School National Exam (ENEM)}

Profesores de una escuela pública paulista analizan el Examen Nacional de la Enseñanza Secundaria

\section{(ENEM)}

Juliana Cristina Perlotti Piunti ${ }^{1}$

Rosa Maria Moraes Anunciato ${ }^{2}$

DOI: http://dx.doi.org/10.20435/serie-estudos.v23i48.1067

\begin{abstract}
Resumo: O ensino médio está em evidência nas atuais discussões políticas sobre educação no Brasil. A reforma que altera significativamente a LDB 9.394/96 coloca em debate as reais e conflitivas demandas dessa etapa de ensino. Em momento paralelo à polêmica da Lei de Reforma do Ensino Médio, tornaram-se públicas as notas do Exame Nacional do Ensino Médio (ENEM), gerando novas discussões na sociedade. Procuramos contribuir para esse debate sobre o ensino médio buscando compreender a perspectiva de professores sobre as repercussões do Exame Nacional do Ensino Médio na sua prática profissional. A análise dos dados de entrevistas com professores de uma escola pública estadual paulista revela que eles consideram que as mudanças constantes no plano curricular prejudicam o ensino médio e dificultam a definição de sua identidade. A partir da literatura sobre política educacional e estudos sobre a docência, aponta-se que os participantes dão novo significado às políticas educacionais no contexto em que as vivenciam como docentes e, assim, evidenciam as contradições no processo de busca por uma identidade para o ensino médio e para a mudança nas práticas docentes.
\end{abstract}

Palavras-chave: ENEM; política avaliativa; docência.

Abstract: The High School is in evidence at the current political discussions about education in Brazil. The reform it through a bill which significantly alters the Education Law (LDB) 9.394/96 and puts in debate the real and conflicting demands from this stage of education. In parallel to the controversy of the High School Reform, the results of the High School National Exam (ENEM)

\footnotetext{
${ }^{1}$ Instituto Federal de São Paulo (IFSP), Câmpus Sertãozinho, São Paulo, Brasil.

${ }^{2}$ Universidade Federal de São Carlos (UFSCar), São Carlos, São Paulo, Brasil.
} 
were made public, generating new discussions from the society. We aim to contribute to this debate about the High School education seeking to understand teachers' perspectives about the repercussions of the High School National Exam in their professional practices. The analysis of the data from interviews with teachers from a public school of the state of São Paulo reveals that they consider the constant changes in the curriculum plan harm the High School education and complicate the process of defining its identity. Based on the literature about educational policy and studies on teaching, it is believed that the participants produce a new signification to the educational policies in the context that they live it as teachers and, therefore, highlight the contradictions in the process of the search for an identity for the High School and for the change at teaching practices.

Keywords: ENEM; evaluative educational policy; teaching.

Resumen: La enseñanza secundaria está en evidencia en las discusiones políticas actuales sobre educación en Brasil. La reforma, que cambia de manera considerable la LDB 9.394/96, pone en debate las demandas reales y conflictivas de esta etapa de enseñanza. En momento paralelo a la polémica de la Ley de la Reforma de la enseñanza secundaria, se publicaron las notas del Examen Nacional de la Enseñanza Secundaria (ENEM), generando nuevas discusiones en la sociedad. Buscamos contribuir para este debate sobre la enseñanza secundaria intentando comprender la perspectiva de profesores sobre las repercusiones del ENEM en su práctica profesional. El análisis de los datos de las entrevistas con los profesores de una escuela pública estadual paulista revela que ellos consideran que los cambios constantes en el plan curricular perjudican la enseñanza secundaria y dificultan la definición de su identidad. Desde la literatura sobre política educacional y estudios sobre la docencia, se puede observar que los participantes dan nuevo significado a las políticas educacionales en el contexto en el que las vivencian como docentes y, así, evidencian las contradicciones en el proceso de búsqueda por una identidad para la Enseñanza Secundaria y para el cambio en las prácticas docentes.

Palabras clave: ENEM; política evaluativa; docencia.

\section{INTRODUÇÃO}

O ensino médio tem sido destaque nas discussões políticas atuais. A Reforma do Ensino Médio, empreendida pela Lei n. 13.417/2017, foi sancionada pelo presidente Michel Temer em fevereiro de 2017 e estabelece a segmentação de disciplinas de acordo com áreas do conhecimento e a implementação gradual do ensino em tempo integral. Essa lei, segundo especialistas, significa um retrocesso a algumas garantias dadas pela Lei de Diretrizes e Bases n. 9.394/96 e as atuais Diretrizes Curriculares do Ensino Médio, como a consideração do ensino médio como etapa final da educação básica obrigatória pautada numa concepção de formação humana integral: científica, ética e estética. São contundentes as críticas sobre o fatiamento do currículo, a ideia de ensino em tempo integral sem garantia de ampliação de investimentos em infraestrutura 
e formação docente, e o desrespeito aos jovens trabalhadores que dependem do ensino médio noturno.

Nesse contexto de aprovação da Reforma, tornaram-se públicas também as notas do Exame Nacional do Ensino Médio, avaliação externa do MEC, que busca indicar a qualidade do ensino ofertado pelas instituições públicas e privadas, e que tem se fortalecido nos últimos anos como uma política avaliativa educacional. Cria-se a oportunidade para se discutir quais os caminhos para um ensino médio público capaz de garantir mais aprendizagem a todos. É nesse sentido que o presente texto buscou apresentar as análises de professores de uma escola pública, para compor uma relação entre a proposta do Exame Nacional do Ensino Médio e o cotidiano de trabalho docente de uma escola de ensino médio pública do interior de São Paulo e analisar algumas implicações para a constituição de sua identidade docente. Como esses professores têm percebido as repercussões da política de avaliação externa na escola? Como interpretam a política pública em si? Como ela impacta seu cotidiano na escola? Estas foram questões que pautaram a proposta de pesquisa com professores da escola estadual de ensino médio, resultando em um estudo que permite discutir relações entre política pública avaliativa e docência. Vivendo um momento político intenso, este debate se faz urgente.

A investigação que deu origem a este artigo teve como temática a perspectiva de professores do ensino médio sobre as repercussões do ENEM em sua prática profissional docente. Foram entrevistados cinco professores do ensino médio de uma escola pública paulista. Em março de 2014, realizou-se um encontro com os professores, no período de planejamento anual do início do ano letivo que teve, além do objetivo de levantamento de novos dados, um viés informativo. Foi projetado um diálogo com os professores, antecedido por uma apresentação da pesquisadora, com o objetivo de expor aos professores e aos gestores a estrutura do atual ENEM e sua relação com o Sistema de Seleção Unificada (SiSU). A intenção era que essa apresentação permitisse aos professores apropriarem-se de informações sobre as possibilidades de ingresso às universidades públicas que o exame abre. As constantes visitas à escola e o diálogo com a equipe gestora foram fundamentais para reconhecimento do espaço, da infraestrutura e da comunidade onde se localiza a instituição. 


\section{O EXAME NACIONAL DO ENSINO MÉDIO NA CONJUNTURA DE UMA POLÍTICA AVALIATIVA EDUCACIONAL}

Em diferentes países, percebe-se a ênfase nas chamadas avaliações de larga escala para medir o desempenho dos estudantes em alguns parâmetros curriculares, definidos idealmente como aqueles que deveriam ser atingidos por todos os estudantes em relação ao currículo escolar. Bonamino e Sousa (2012) identificam três gerações de avaliações da educação em larga escala, que coexistem no âmbito das redes de ensino e apresentam consequências diferenciadas para o currículo escolar. A primeira geração enfatiza a avaliação com caráter diagnóstico da qualidade da educação ofertada, mas não há atribuição de consequências diretas para as escolas e para o currículo. Seus resultados são geralmente divulgados na Internet e disseminados pela mídia, sem devolução para as escolas avaliadas. Avaliações de segunda geração contemplam, além da divulgação pública, a devolução dos resultados para as escolas, sem estabelecer consequências materiais, mas simbólicas. Avaliações de terceira geração referenciam políticas de responsabilização com sanções ou recompensas em decorrência dos resultados de alunos e escolas (BONAMINO; SOUSA, 2012, p. 375).

Uma das consequências simbólicas das avaliações é materializada na divulgação pela mídia dos chamados rankings das melhores escolas, nos quais figuram geralmente as escolas de prestígio, que atendem a uma clientela de maior poder aquisitivo. O ranqueamento das escolas de todo o país e a ampla divulgação pela mídia atinge, de forma direta, alunos e professores, sujeitos geralmente responsabilizados pelo sucesso ou fracasso dos resultados da escola. Para Silva (2003, p. 258), os exames ao final de um determinado percurso traduzem uma concepção tradicional de avaliação e de currículo que manifesta a intenção de controle. Para as finalidades da reforma do ensino médio, o controle tende a se viabilizar sobre os "indivíduos convertidos em alvos das prescrições curriculares - alunos e professores". Quanto aos alunos, seu desempenho mostraria a eficácia das proposições, ou a ausência dela. No caso desta segunda possibilidade, o controle deveria recair mais sobre os professores, que "falharam por não incorporarem com exatidão as proposições".

As tentativas de reforma do ensino médio que ocorrem desde a Lei de Diretrizes e Bases da Educação Nacional n. 9394/96, apresentam a essência de uma política pública para a educação, na medida em que é expressa num corpo 
de leis, regulamentos, decisões e ações do governo. Os currículos vigentes para o ensino médio, materializados nas mais recentes diretrizes curriculares (BRASIL, 2011), configuravam, até recentemente, o principal eixo dessa reforma e, portanto, dessa política. O ENEM configurou-se como a avaliação externa desse processo implementado. Os órgãos oficiais, especialmente o Instituto Nacional de Estudos e Pesquisas Educacionais (INEP), garantem que o exame veio para avaliar a efetivação de um currículo e, portanto, seria um instrumento de indução de mudanças das práticas docentes, no sentido de permitir a concretização da proposta.

Ball e Mainardes (2011) têm sinalizado que as políticas, particularmente as educacionais, em geral são pensadas e escritas para contextos que possuem infraestrutura e condições de trabalho adequadas (seja qual for o nível de ensino), sem levar em conta variações enormes de contexto, de recursos, de desigualdades regionais ou das capacidades locais. Também indicam que a política pode estar relacionada à organização das práticas e à relação que elas têm com alguns tipos de princípios. Porém elas não são fixas e imutáveis e estão sujeitas a interpretações e traduções e compreendidas como respostas a problemas da prática. Para esses autores, as políticas estão sempre em algum tipo de fluxo, no processo de se tornarem algo mais, e esse é, fundamentalmente, o caso atual da educação, que flui ao lado da política (declarações, demandas e expectativas).

A reforma do ensino médio pautada nas diretrizes curriculares nacionais seria, portanto, uma declaração de mudanças no ensino, para atender a uma nova demanda - em síntese, as necessidades impostas pelo mercado à sociedade atual de jovens e a suposta falta de identidade do ensino médio. A expectativa seria de que essa reforma, como um todo, suprisse essa nova demanda, atingindo os professores em suas práticas, garantindo diferentes aprendizagens aos egressos do ensino médio. Espera-se que o ENEM, ao avaliar os alunos, sirva de impulso à colocação em prática do novo currículo estruturado, especialmente sob os conceitos de contextualização, interdisciplinaridade, competências e habilidades. Mesmo com o Parecer CNE/CEB n. 5/2011, aprovado em 4 de maio de 2011, que define as Diretrizes Curriculares Nacionais para o Ensino Médio (BRASIL, 2011), o exame continua ancorado na ideia de competências e habilidades que contornou a identidade das Diretrizes anteriores (Parecer 15/98). Destaca-se que essa perspectiva de reforma analisada não considera a Lei 34/2016, que reforma o Ensino Médio, sancionada em fevereiro de 2017. 
Enfim, professores do ensino médio e quem convive com seus estudantes sabem que uma das principais motivações para participação no ENEM é a "possibilidade concreta de carimbar o passaporte de ingresso no ensino superior", uma vez que os resultados obtidos no ENEM podem ser utilizados como requisito parcial ou total em processos seletivos para ingresso nesse nível de ensino (BRASIL, 2011). A centralização dos exames seletivos, a partir do ENEM, que supostamente democratizaria o acesso a todas as universidades, tomou forma com a implantação do SiSU. De acordo com o artigo $1^{\circ}$ da Portaria Normativa n. 2/2010:

Art. $1^{\circ}$ Fica instituído o Sistema de Seleção Unificada- SiSU, sistema informatizado gerenciado pelo Ministério da Educação- MEC, por meio do qual são selecionados candidatos a vagas em cursos de graduação disponibilizadas pelas instituições públicas de educação superior participantes. $\S 1^{\circ}$ A seleção dos candidatos às vagas disponibilizadas por meio do SiSU será efetuada exclusivamente com base nos resultados obtidos pelos estudantes no Exame Nacional do Ensino Médio - ENEM. (BRASIL, 2010).

Na prática, a partir do desempenho no ENEM, os alunos se inscrevem no site do SiSU e aguardam a convocação para matrícula, mediante a aprovação para o curso e a universidade por ele escolhidos. Para isso é preciso atingir a nota mínima que a graduação exige no ENEM. Além do SiSU, o ENEM possibilita a participação em programas governamentais de acesso ao ensino superior, como o Programa Universidade para Todos (ProUni). Este, segundo o site do Ministério da Educação (MEC), é um programa desse Ministério, criado pelo governo federal em 2004, que concede bolsas de estudo integrais e parciais (50\%) em instituições privadas de ensino superior, em cursos de graduação e sequenciais de formação específica, a estudantes brasileiros sem diploma de nível superior. Nesse programa, podem participar estudantes egressos do ensino médio da rede pública ou da rede particular, na condição de bolsistas integrais da própria escola; estudantes com deficiência; professores da rede pública de ensino do quadro permanente que concorrerem a cursos de licenciatura e, nesse último caso, não é necessário comprovar renda. Para concorrer às bolsas integrais, o candidato deve comprovar renda familiar bruta mensal, por pessoa, de até um salário mínimo e meio. Para as bolsas parciais (50\%), a renda bruta familiar deve ser de até três salários mínimos por pessoa.

O ENEM foi pensado como um possível indutor de práticas docentes, na medida em que induziria os alunos e a sociedade, de uma forma geral, a cobrar 
respostas da escola e dos professores em direção à melhoria da qualidade do ensino ofertado, concomitantemente a outras ações do Estado na direção da reforma do ensino médio. Acredita-se também que o ENEM seria um referencial para os professores reformularem suas práticas de ensino segundo os princípios norteadores da matriz de referência, utilizando, por exemplo, as noções de competências, habilidades, interdisciplinaridade e contextualização. Porém a interpretação do professor sobre o texto das políticas educacionais é que irá definir sua prática e, nesse sentido, não são os professores simplesmente executores de algo já estabelecido por outrem. Saber como a política avaliativa do ENEM é vivida e ressignificada pelos atores sociais, os professores, é onde reside, enfim, o interesse para o contexto da prática, ou seja, para a forma como têm os professores compreendido essa avaliação.

Abordar o ENEM como uma política avaliativa educacional traz a necessidade de rever alguns pontos sobre a temática da avaliação e sua relação com a docência. Sousa (2003) e Bonamino e Sousa (2012) afirmam que hoje se observam propostas e práticas que, para além da avaliação do aluno, voltam-se para a avaliação do desempenho docente, a avaliação de curso, a avaliação institucional, a avaliação do sistema educacional. É nesse contexto que se inserem a criação e o fortalecimento do ENEM. Os atuais modelos de avaliação externa aplicados no Brasil, como o ENEM, pautam-se nas seguintes características (SOUSA, 2003): ênfase nos produtos ou resultados; atribuição de mérito, tomando-se individualmente instituições ou alunos; dados de desempenho escalonados, resultando em classificação; uso de dados predominantemente quantitativos; destaque à avaliação externa, não articulada à autoavaliação. Nesse contexto em que a avaliação externa assume um papel de fortalecimento de práticas docentes pautadas na busca por resultados externamente condicionados, como se configura a escola? Como os professores percebem os efeitos dessa avaliação na escola? Como eles se apropriam da política avaliativa educacional que o ENEM representa? São questões que também pautaram o percurso metodológico da pesquisa.

\section{AS ANÁLISES DE PROFESSORES DE UMA ESCOLA PÚBLICA PAULISTA SOBRE O ENEM}

Na pesquisa realizada, percebeu-se que as mudanças nas práticas profissionais são tão mais visíveis quanto mais fortes e estreitas são as relações entre 
os profissionais. Nota-se também quando os profissionais se identificam com a comunidade em que trabalham. Assim, se existe a possibilidade de o ENEM transformar a vida dos estudantes com os quais convive, o professor muda suas estratégias. Saulo, professor de sociologia, é ex-aluno da escola, Gilberto atua há 20 anos na mesma escola, assim como Helena e Laura. Os dois primeiros organizaram o curso pré-vestibular em uma instituição religiosa do bairro onde fica a escola, e as outras professoras foram responsáveis por aulas voluntárias que buscavam preparar os alunos para o ENEM. A própria gestora indicou que são esses professores com forte identificação com a escola que têm mudado práticas pedagógicas para preparar os alunos para o ENEM.

Tanto o professor menos experiente como o mais experiente, coletivamente, estão modificando - ou querem modificar - suas práticas e dando novos sentidos ao fazer docente, promovendo a reconstrução da identidade profissional pautada pela lógica regulatória que o ENEM, como avaliação externa somativa, tem construído. Também são esses os professores com as visões mais críticas sobre as políticas educacionais atuais. Ou seja, eles modificam as práticas, mesmo sabendo dos limites da conjuntura política e econômica vigente. A coordenadora da escola afirmou:

Nossa clientela é ainda uma clientela muito pobre que não faz o ensino médio pensando no ensino superior. Faz pensando em arrumar um emprego qualquer. Apesar que a gente percebe que os terceiros colegiais quando eles chegam no terceiro eles são [...] peneirou um pouco mesmo. Só aqueles melhores que chegam lá mesmo, os outros param no meio do caminho. Mas, mesmo assim, eu posso dizer pra você que $70 \%$ dos nossos alunos estão fazendo ensino médio por fazer, não têm aquela pretensão de seguir uma carreira, só querem arrumar um emprego para viver mesmo e nada mais. (Cássia).

O fato de trabalharem com jovens que pertencem às classes de baixa renda tem repercussão na forma como os professores se mobilizam em relação ao direcionamento de suas aulas. Todos os professores enfatizaram o fato de a maioria dos alunos não se identificar com um percurso pós-ensino médio na universidade. 0 professor Gilberto, de geografia, durante o debate sobre as diferentes concepções de formação que as Diretrizes Curriculares Nacionais para o Ensino Médio trazem, em 1998 e depois em 2011, citou o fato de os alunos que trabalham e estudam à noite receberem um valor hora trabalhada em uma empresa multinacional bem 
maior que o que ele recebia como professor. Para ele, esta era uma situação constrangedora e controversa, porque ele se sentia impotente diante de uma situação em que os jovens não enxergavam sentido em continuar os estudos no ensino superior, pois era mais viável, diante de suas condições de vida, inserir-se logo no mercado de trabalho. Isto o levava a refletir sobre as próprias contradições do mundo do trabalho e das expectativas dessa juventude.

Para Fanfani (2010), é perceptível uma crise no modelo tradicional da escola de nível médio, na medida em que as condições dos professores e dos alunos têm mudado, assim como têm mudado as demais condições sociais, sem que, contudo, a escola de nível médio tenha acompanhado tais mudanças. Uma das constatações que o levam a essa tese é a de que os jovens e suas famílias estão conscientes de que a escola como "ascensor social" deixou de funcionar. Segundo o autor, a escola média se massificou, porém, o crescimento dos títulos escolares não foi acompanhado por um crescimento proporcional dos empregos e das ocupações que o mercado de trabalho oferece. Sendo assim, o desequilíbrio entre a massificação da escolaridade e a consequente proliferação de títulos diante de um mercado de trabalho restringido constitui um fator de desestímulo ao esforço escolar. Isso explicaria, em parte, o desinteresse e a evasão cada vez maior, no Brasil, dos alunos nessa etapa de ensino.

Pois é exatamente nesse contexto de conflitos, de resistências e de expectativas (nem sempre alcançadas) que atuam os professores com os quais se dialogou. Merece destaque o otimismo com que a maioria dos professores enxerga o ENEM, a partir do momento em que ele se constitui uma possibilidade de seus alunos acessarem o ensino superior. Beto afirma:

Acredito que trouxe impactos positivos porque nossos alunos aqui eles têm a cada ano que passa melhorado a nota deles no ENEM. Tem alunos bastante estudiosos nesse sentido, que puseram objetivo lá de atingir uma nota de excelência no ENEM, até mesmo para que eles possam estar dando continuidade no estudo, mesmo com o poder aquisitivo baixo, eles conseguindo aí entrar numa faculdade aí através do ProUni, através de outros mecanismos que possa estar colaborando com eles nesse sentido (Beto).

Chama-nos atenção a identidade que o professor constrói para si, como motivador do aluno, como criador de expectativas para aqueles alunos que enxergam no ENEM a possibilidade de continuidade dos estudos. É também uma 
forma de superar as dificuldades do dia a dia da escola. Para Beto, "a ampliação de acesso ao ensino superior motiva professores e alunos, gera determinação, amplia e diversifica as práticas docentes". Num contexto de adversidades, estes professores se sentem reconhecidos, valorizados, quando percebem o sucesso dos alunos em relação ao prosseguimento dos estudos no ensino superior. Para Mário, há reconhecimento da escola e do empenho do professor. Um sinal muito forte da identidade docente que aparece no contexto da pesquisa é o aluno como motivador profissional do professor.

Para Helena, faltam diálogo e trabalho colaborativo, por isso o impacto em relação aos docentes é baixo. Para ela, não há conhecimento da proposta de avaliação e discussão dos conceitos que embasaram o currículo avaliado. Sabese que o processo de implementação de uma política educacional não é simples e linear. Ainda mais quando envolve as intenções de uma avaliação externa e a transformação do currículo. Ball (1994) argumenta que, para uma política ter legitimidade e efetivar-se como legítima, é fundamental conhecer como os sujeitos e os grupos a interpretam e a ressignificam - ou não - para a sua realidade. No mesmo sentido, "a capacidade de efetivação da implementação de uma política está centrada na condição de leitura e devolutiva dos contextos para os quais foram elaboradas e da dialogicidade com os atores sociais ou implementadores em relação à sua ressignificação" (LIMA; MARRAN, 2013, p. 54).

Para Saulo, falta trabalho coletivo entre os docentes e entre estes e a gestão. E o isolamento do professor aparece como uma desorientação, como falta de um projeto de escola. O descompasso entre os documentos escritos (propostas) e as práticas (estratégias) de atuação é uma constante na fala deste professor. Para ele, as orientações passadas pelo governo deixam os professores confusos e não expressam a realidade da escola. Segundo Saulo, há demanda por formação docente e pela discussão das finalidades da escola. Em sua fala, o trabalho coletivo de docentes e gestão e a organização com objetivos mais claros seria uma forma de criar uma identidade para a escola. Percebe-se, portanto, que o ENEM acaba por configurar-se como um objetivo para professores e alunos, na medida em que esse exame cria uma identidade para o ensino médio, qual seja, a de preparar os estudantes para o ensino superior. Aqui não há grande alteração de identidade, pois o papel do ensino médio foi, por muito tempo, o de trampolim para a universidade. A diferença é que, se antes esta era a identidade do ensino médio 
das classes privilegiadas financeiramente, hoje a ideia de um curso preparatório para o acesso ao ensino superior abarca representantes de classes desfavorecidas que frequentam a escola pública. O que não sugere afirmar que houve democratização de acesso à universidade, mas, sim, a facilitação do acesso para aqueles que estiveram por muitas décadas distantes de uma formação pós-ensino médio.

Como afirma a professora coordenadora, são poucos os alunos que enxergam o ENEM como uma oportunidade. Há duas preocupações aqui: uma que é reflexo da brutal evasão que ocorre entre os primeiros e os terceiros anos do ensino médio, possibilitando a poucos alunos que concluem esta etapa realizar o ENEM como mecanismo de acesso ao ensino superior; a outra é o fato de a maioria dos que concluem o nível médio partir para o ensino superior privado, devido à falta de informação sobre as oportunidades que o ensino superior público oferece.

Para Saulo, o fato de a maioria dos professores ser formada em faculdades privadas incrementa a dificuldade de incentivo aos alunos para ingressar no ensino superior público. Também é evidente uma crença da maioria dos alunos que frequentam a escola pública, de que para eles é impossível acessar o ensino superior público. Assim afirma Helena, comparando-os aos alunos das escolas médias privadas. Essa falta de perspectiva da juventude, dos que não têm "incentivos", pode ser analisada como um recorte específico, qual seja, o de grupos sociais que não têm um histórico familiar de acesso ao ensino superior, ou mesmo, que não se identificam com a universidade pública, pois seus professores não foram formados por ela. Mas também denota desconhecimento dos anseios e das razões dessa juventude. O "vir a ser" (FANFANI, 2010) não é uma constante para os jovens pobres, diferentemente do que ocorre nas classes mais favorecidas, que têm projetos familiares traçados de carreira e futuro para seus filhos. As condições em que vivem os jovens da periferia urbana no Brasil não são reconhecidas por todos os seus professores, que ainda são representantes de classes mais favorecidas que seus alunos (GATTI; BARRETO, 2009). O acesso ao ensino superior é uma meta importante, mas não pode se constituir em uma única estratégia de identificação do ensino médio.

Para Laura, o grande impasse da educação é dar sentido ao conhecimento transmitido na escola. Motivar o aluno a estar na escola e levá-lo a ver nela perspectiva de futuro é o impasse no ensino médio. Laura e outros professores perceberam que o ENEM é uma motivação para eles, e os que almejam a continuidade 
dos estudos participam mais, veem mais sentido na escola e no conhecimento que ali se constrói. Isso é favorável para os professores, pois os aproxima dos alunos e torna mais fácil a relação de ensino e aprendizagem. Daqui se podem tirar algumas lições: além do ENEM, outros mecanismos e estratégias políticas poderiam dar outro contorno de identidade para o ensino médio, possibilitando aos seus alunos participarem mais, enxergarem mais sentido no conhecimento que ali se produz. Há que considerar que nem todos os jovens têm os mesmos anseios em relação ao futuro. Reconhecer isso é pensar que todo projeto de construção de identidade para o ensino médio deve partir do reconhecimento da diversidade que o configura. Nesse sentido, colocar o ENEM como balizador das práticas pedagógicas, identificando-o com o próprio currículo, seria uma condição limitante de política educacional projetada para o nível médio, embora ele se configure como um motivador para alunos que, após um grande movimento de evasão, permanecem nos terceiros anos.

As falas dos professores também indicam perspectivas sobre a política educacional que envolve o ENEM. Elas sinalizam a forma como esses professores se posicionam como sujeitos que ressignificam políticas educacionais no contexto da prática. E permitem compreender como as escolas lidam com as múltiplas demandas, muitas vezes contraditórias das políticas implementadas, como a de avaliação externa.

Os professores parecem construir uma ideia sobre a política pública que é fruto do desconhecimento, da perspectiva de não enxergar na política, ou no currículo, uma proposta de melhoria. A percepção verbalizada é a de que a política demora muito para chegar à escola. Isso vai trazendo um desconforto, um descrédito, contribuindo para ampliar o mal-estar docente. Como afirmou o professor Saulo: "As orientações do governo do Estado deixam os professores muito confusos".

As falas dos professores indicam que, por vários motivos, não há uma efetiva incorporação dos pressupostos teóricos e curriculares que o ENEM buscou induzir nas práticas dos professores. Transformar o ensino médio em um curso pré-ENEM não é indicativo de que os professores estejam "reformando o ensino médio" na direção do que pressupõem as diretrizes curriculares para essa etapa de ensino. Mas, por outro lado, indicam outras possibilidades de atuação do professor diante dos dilemas que esse nível de ensino enfrenta. 
Nesse cenário de propostas de alterações curriculares e avaliações externas, deve-se lembrar também que a mudança social contemporânea tem transformado profundamente o trabalho dos professores, sua imagem e o quanto a sociedade valoriza sua tarefa, segundo Marcelo e Vaillant (2009). Para esses autores, a transformação dos nossos sistemas educativos tem gerado problemas novos que ainda não assimilamos. O desconcerto, a falta de preparação para afrontar o novo e a intenção de manter rotinas levam muitos professores a se exporem a uma crítica generalizada e os colocam como os responsáveis universais por todas as falhas do sistema de ensino. Tem-se, portanto, a certeza de que o papel do professor tem se transformado, entre outras razões, porque ele deve assumir um maior acúmulo de responsabilidades, e em razão do aumento das exigências as quais se encontra submetido.

Os professores entrevistados, em geral, mostram uma receptividade positiva e otimista da proposta avaliativa do ENEM. "Eu penso que tem que existir realmente essas avaliações externas, que avaliação externa veio para contribuir bastante com a educação, com a escola em si", afirma Beto. Mário reconhece a avaliação como prática para melhorar o ensino e a aprendizagem. Para Laura, o ENEM apresenta limites enquanto avaliação da aprendizagem, mas seu mérito está em permitir, ao aluno da escola pública, o acesso ao ensino superior de forma facilitada, se comparado aos demais vestibulares. As vozes dos professores não são convergentes em todos os aspectos que envolvem as repercussões do ENEM na escola e em suas práticas. Beto, por exemplo, é um professor que assume o discurso dos benefícios da competitividade, da produtividade, que são próprios da lógica que envolve o modelo de avaliação externa que o ENEM representa, na medida em que promove o ranqueamento das instituições e dos alunos. É válido lembrar que Beto atua na rede estadual há mais de 20 anos, porém atualmente possui uma jornada mínima de 10 horas aulas, pois é diretor de uma escola privada no município. Ele parece identificar-se com o modelo privado de ensino e considera positiva a avaliação, pelo seu caráter indutor de competitividade entre alunos, professores e gestão. Para ele, a disputa entre esses sujeitos é "produtiva". Helena expressa o caráter provisório das mudanças voltadas para a escola pública estadual. Ela aceita o ENEM como modelo inovador de avaliação que supostamente democratizaria o acesso às universidades federais, ao mesmo tempo em que apresenta desconhecimento da política: 
Eu sinto que a escola do Estado ela é uma grande cobaia. Tem uma proposta que vem lá do governo federal, veio o ENEM que é maravilhosa, do meu ponto de vista, é super legal. Nas universidades federais, depois de você fazer o ENEM e tentar depois umas vagas remanescente. Democratização do acesso. É isso? É. O fundamental de tudo isso é como que é, como foi elaborado? E como que eu trabalho isso? Eu preciso conhecer. (Helena)

Para Saulo, o ENEM oferece acesso ou facilidade às universidades federais, mas para ele parece contraditório falar em democratização de acesso ao ensino superior, pois há criação de muitas vagas para o ensino superior privado. Saulo é um professor iniciante na rede pública, mas possui um olhar bastante elaborado sobre a política educacional que envolve o ENEM. Ao falar sobre o financiamento das faculdades particulares e da transformação do ensino superior em mercadoria, faz referência ao Programa Universidade para Todos (ProUni) do Ministério da Educação, que concede bolsas de estudo integrais e parciais em instituições privadas de ensino superior.

Mário afirma que a efetividade da política depende do professor, da sua vontade. Porém ele também justifica que o desânimo desse profissional em relação às mudanças tem a ver com a falta de respaldo do governo, a desvalorização profissional. Helena reconhece e identifica as demandas que o ENEM gera: formação inicial e continuada com qualidade. E também sinaliza uma crítica à expansão dos cursos privados de formação inicial e à falta de investimento para formação continuada. Ela argumenta contra as propostas do Estado que vêm "de cima para baixo", ou seja, sem considerar a perspectiva do professor; destaca a questão da elaboração de material didático que vá ao encontro da proposta avaliativa; e aponta a necessidade de criação de espaços para a discussão entre professores na própria escola, no sentido de permitir a interlocução entre as áreas do conhecimento e a atualização desses profissionais.

A falta de material, formação e espaço de diálogo, na própria escola, para os profissionais se sentirem preparados para lidar com o ENEM apareceu como constante nas falas dos professores. Para Helena, o grupo gestor tem papel fundamental na criação de espaços para diálogo. Ela também considera importante a coesão entre os profissionais e identifica o problema da rotatividade de professores no corpo docente escolar.

Segundo Arretche (apud LIMA; MARRAN, 2013, p. 52), é crucial conhecer a condição institucional para a implementação da política, pois, mesmo os 
implementadores conhecendo a política, sendo favoráveis a seus objetivos e regras, se houver problemas institucionais, eles terão sérias dificuldades para a implementação e o atendimento aos objetivos desejados. Devemos ter em mente que são os implementadores que fazem a política, e as condições em que a desenvolvem são fundamentais para seu sucesso. A identificação do professor com a proposta também parece uma medida razoável para que seja implementada. E, para haver identificação com a proposta, a aprendizagem do professor é condição sine qua non.

A falta de formação e a resistência de professores, além das orientações pouco claras, aparecem para Saulo como motivos para a confusão em torno da política do ENEM. Para este professor, nos documentos oficiais, não há indicativos de estratégias ou de como o professor deve atuar em relação às propostas educacionais. E o isolamento de alguns profissionais, as tentativas individuais de trabalho não podem garantir a mudança planejada. Mais uma vez aparecem indícios do contexto da prática, ou seja, das condições em que deveriam ser pautadas as propostas educacionais oficiais. Como afirma Saulo, não é possível pensar a escola como uma "ajuntação de átomos".

O trabalho colaborativo é uma das formas de os professores constituírem e fortalecerem sua identidade, possibilitando o desenvolvimento profissional. No entanto o isolamento continua sendo um forte sinal da identidade docente. Ter os professores como consumidores das políticas educacionais, "de cima para baixo", como disseram alguns professores, também implica o fortalecimento da identidade do professor como implementador da política ao acaso, sem a possibilidade de construção de "estratégias didáticas de como interferir" (Saulo).

"Com o desprestígio sentido de forma atroz, o professor sendo feito de cobaia, tal qual a escola pública, quem quer seguir a docência hoje?" questionou-se Helena. A desvalorização profissional expressa na falta de professores para áreas específicas é só um exemplo das circunstâncias em que se encontra o professor, segundo sua perspectiva. O sentimento de desvalorização profissional aparece de forma evidente quando se relembra a trajetória das políticas educacionais, feitas de governo em governo. Diante desse desprestígio profissional e da precarização do trabalho no ensino médio, como é possível a esperança ainda teimar em existir? Como é possível Helena afirmar: "Eu acredito ainda, por incrível que pareça. Acredito que possa mudar"? O que mantém o professor hoje na escola em meio a tanto mal-estar? 
A pesquisa apontou que, diante das mudanças projetadas a partir da avaliação externa, o professor se encontra em um "sistema de regulação pelos resultados" (MAROY, 2012). Nesse sistema, arquitetado a partir de uma avaliação externa somativa e dotado do efeito de suposta democratização de acesso ao ensino superior, mediante o papel do ENEM, o professor do ensino médio reforça algumas identidades profissionais e assume novas, possibilitando, em alguns momentos, seu desenvolvimento profissional, mas ao mesmo tempo destacando seus limites. O professor se pauta em estratégias individuais. Ele olha para o aluno/indivíduo, altera sua prática em relação a esse aluno atendendo a demandas pontuais e específicas. Ele não altera a prática pedagógica como um todo, a relação com o conteúdo, por exemplo. As práticas coletivas não são alteradas substancialmente, e assim a escola não muda.

O trabalho isolado, as oportunidades de práticas docentes específicas e o consumo não refletido da proposta política são algumas das condições em que o professor assume sua identidade profissional. A busca "artesanal" (HUBERMAN, 1993) pelo fazer docente, a motivação encontrada no aluno e no papel que possui de incentivador dos seus alunos fazem o professor buscar, quase sempre de forma isolada, o seu desenvolvimento profissional: conhecer a prova do ENEM; criar exercícios e provas para os alunos, treinando-os; rever estratégias de ensino para um novo currículo; diversificar as práticas de ensino etc. No entanto, o que mantém o professor hoje na escola, diante do mal-estar que as políticas implementadas "de cima para baixo", de forma descontínua, sem a devida formação que ela demanda, sem as necessárias condições institucionais para efetivá-la, nas condições de desvalorização ("desprestígio") em que o profissional docente se encontra?

A pesquisa permitiu considerar que ter o aluno como motivador e enxergar o sucesso do estudante diante de seu futuro no ensino superior, proporcionado pelas facilidades que o ENEM criou, leva os professores a criarem estratégias de ensino específicas, para alunos específicos. Nessa conjuntura, o professor se identifica como um criador de expectativas para os alunos, que, apesar da grande evasão no final da educação básica, permanecem no terceiro ano do ensino médio. Seja buscando alternativas em práticas como as aulas voluntárias, seja diversificando estratégias em busca de um ensino que atinja mais estudantes, os professores continuam acreditando na política educacional, especialmente quando estão 
vinculadas às propostas de suposta democratização de acesso ao ensino superior, como o ENEM. A crença na inovação curricular e no seu potencial também aparece, apesar das críticas em relação ao modelo de implementação que não centraliza o professor como protagonista nas relações de ensino. A docência no ensino médio apresenta peculiaridades que intensificam o desgaste do fazer docente, diante de uma juventude cada vez mais heterogênea, de jornadas exaustivas, de planos de carreira pouco recompensadores, enfim, numa etapa de ensino que carece de políticas que deem mais sentido para todos que a frequentam, inclusive para os professores.

\section{CONSIDERAÇÕES FINAIS}

O ensino médio é vítima de reformismo constante ao longo de sua história. A conquista legítima de um ensino médio público como educação básica e obrigatória é recente. A evasão, o fracasso escolar, o descontentamento de estudantes e a falta e condições de trabalho de professores são alguns dos problemas a serem enfrentados. Para que seja alcançado um ensino médio público, gratuito e de qualidade que atenda aos anseios de uma juventude garantindo uma formação integral pautada na ciência, tecnologia e cultura, transformações são necessárias. Diversas pesquisas em educação sinalizam os caminhos a serem escolhidos para essa trajetória. Aqui nos concentramos em refletir sobre como os professores lidam com esse reformismo constante, especificamente com a política que envolve o ENEM. É necessário ouvir aqueles que vivem as escolas (PIUNTI; OLIVEIRA, 2010).

Discutir os impactos do ENEM na escola, na visão dos professores, permitiu identificar sua sensibilização para as condições e os objetivos de vida de seus alunos; o sentimento de valorização e reconhecimento diante do sucesso dos alunos; a desorientação diante das propostas políticas para a escola; e a identificação desses profissionais com o papel de mobilizadores, incentivadores dos alunos, a relação entre docência e política educacional e sobre condições gerais do trabalho do professor na escola pública. Na perspectiva dos professores entrevistados, constata-se que as políticas demoram para chegar na escola; há desconhecimento de propostas e desvalorização dos saberes do professor na formulação das políticas;

há descontinuidade e rupturas no processo de implementação e concretização de propostas políticas educacionais; há dificuldades de transformar os documentos 
oficiais em propostas práticas de ensino; há dificuldades institucionais (falta de coesão entre gestão e corpo docente) para discutir e implementar mudanças; e há reconhecimento das contradições que envolvem as propostas políticas, desde as curriculares como as avaliativas.

Ficam evidentes as contradições que permeiam a relação do professor com a política educacional. Pessoas concretas lidam com a vida real, com as contradições. Os professores sujeitos da pesquisa desconhecem os "documentos de gabinete", aqueles que representam, por exemplo, os objetivos gerais e específicos do ENEM, a sofisticação do seu método avaliativo e suas potencialidades. Eles desconhecem as especificidades que marcam os documentos curriculares vigentes. No entanto, nesse contexto de desconhecimentos, de falta de identidade que tem marcado o ensino médio, vítima de um inconsequente reformismo histórico, acrescido das evidentes condições que expressam a desvalorização do trabalho do professor, o ENEM surge como uma materialidade a se apegar. Ele representa, para esses professores, um instrumento de avaliação que pode dar significados a sua prática em sala de aula, ao gerar expectativas em seus alunos. E, numa espécie de carência total, os professores se agarram a essa materialidade.

O ENEM se configura, para os alunos, como uma expectativa de acesso ao ensino superior que tem sensibilizado e mobilizado esses docentes. Dessa forma, ao mesmo tempo em que a política imposta gera inconformismo por ser identificada com as mudanças constantes no plano curricular que dificulta o contorno de identidade do ensino médio, a política avaliativa do ENEM gera também uma possibilidade de questionamento e alteração das práticas docentes. É, enfim, um retrato do processo de busca pela criação de identidades para o ensino médio e para a mudança nas práticas docentes.

\section{REFERÊNCIAS}

BALL, S. J. Education reform: a critical and post-structural approach. Buckingham and Philadelphia: Open University Press, 1994.

BALL, S. J.; MAINARDES, J. (Org.). Políticas educacionais: questões e dilemas. São Paulo: Cortez, 2011.

BONAMINO, A.; SOUSA, S. Z. Três gerações de avaliação da educação básica no Brasil: interfaces com o currículo da/na escola. Educação e Pesquisa [online], São Paulo, v. 38, n. 2, p. 373-88, abr./jun. 2012. 
BRASIL. Lei n. 13.145, de 16 de fevereiro de 2017. Altera a Lei n. 9.394, de 20 de dezembro de 1996, que estabelece as diretrizes e bases da educação nacional. Disponível em: <http://www.planalto.gov.br/ccivil_03/_ato2015-2018/2017/lei/l13415.htm>. Acesso em: 21 maio 2018.

. Câmara de Educação Básica do Conselho Nacional de Educação. Parecer CNE/ CEB n. 5, de 4 de maio de 2011. Institui as Diretrizes Curriculares Nacionais para o Ensino médio. Disponível em: <http://portal.mec.gov.br/index.php? option=com_content\&vie $w=$ article\&id=16368\&ltemid=866>. Acesso em: 22 jul. 2012.

. Ministério da Educação (MEC). Instituto Nacional de Estudos e Pesquisas Educacionais Anísio Teixeira (INEP). Resumo técnico - Censo Escolar. Brasília, 2010.

. Lei n. 9.394, de 20 de dezembro de 1996. Estabelece as diretrizes e bases da educação nacional. Disponível em: <http://www.planalto.gov.br/ccivil_03/Leis/L9394. htm >. Acesso em: 21 maio 2018.

FANFANI, E. T. Los que ponen el cuerpo. El profesor de secundaria en la Argentina actual. Educar em Revista, Curitiba, PR, v. 26, número especial, p. 37-76, set. 2010. Disponível em: <http://revistas.ufpr.br/educar/article/view/20464>. Acesso em: 27 abr. 2017.

GATTI, B. A.; BARRETO, E. S. de S. Professores do Brasil: impasses e desafios. Brasília: UNESCO, 2009. Disponível em: <http://unesdoc.unesco.org/images/0018/001846/184682por.pdf>. Acesso em: 20 fev. 2015.

HUBERMAN, M. The model of the independent artisan. In: LITTLE, J. W.; MCLAUGHLIN, M. W. (Ed.). Teachers' professional relations in teachers' work. Individual, colleagues and contexts. Chicago: Teacher College Press, 1993.

LIMA, P.; MARRAN, A. A avaliação de políticas educacionais por meio da abordagem teórico-analítica do ciclo de políticas. Práxis Educativa, Ponta Grossa, PR, v. 8, n. 1, p. 41-62, jan./jun. 2013. Disponível em:<http://www.revistas2.uepg.br/index.php/praxiseducativa/ article/view/5370>. Acesso em: 20 fev. 2015.

MARCELO, C.; VAILLANT, D. Desarrollo professional docente. Cómo se aprende a enseñar? Madrid: Narcea, 2009. 176p.

MAROY, C. Towards post-bureaucratic modes of governance. In: STEINER-KHAMSI, G.; WALDOW, F. (Ed.). World yearbook of education 2012: policy borrowing and lending in education. London: Routledge, 2012. p. 62-93.

PIUNTI, J. C. P.; OLIVEIRA, R. M. M. A. de. Processos de socialização: diferentes aprendizagens em um curso pré-vestibular. Série-Estudos, Campo Grande, MS, n. 30, p. 383-97, jul./dez. 2010. Disponível em: <http://www.serie-estudos.ucdb.br/index.php/ serie-estudos/article/view/203/206>.

SILVA, M. R. Competências: a pedagogia do "novo Ensino médio". 2003. Tese (Doutorado em Educação)- Pontifícia Universidade Católica de São Paulo (PUC-SP), São Paulo, 2003. 
SOUSA, S. M. Z. L. Possíveis impactos das políticas de avaliação no currículo escolar. Cadernos de Pesquisa, São Paulo, n. 119, p. 175-90, jul. 2003.

\section{Sobre os autores:}

Juliana Cristina Perlotti Piunti: Professora de Sociologia no Instituto Federal de São Paulo, câmpus Sertãozinho. E-mail: julianapiunti@ifsp.edu.br

Rosa Maria Moraes Anunciato: Professora do Departamento de Teorias e Práticas Pedagógicas e do Programa de Pós-Graduação em Educação da Universidade Federal de São Carlos. E-mail: rosa@ufscar.br

Recebido em maio de 2017

Aprovado em maio de 2018 